\title{
The Economics of Ecosystems and Biodiversity: Ecological and Economic Foundations
}

Pushpam Kumar (ed). Earthscan, London, 2010. xxxix +410 pp. Price £49.99 (hardback). ISBN 978-1-84971-212-5.

Essentially this is a giant review of the environmental economics literature, notable principally for how well it has been promoted. It contains a large compendium of individual studies in the form of a set of appendices, and it is the specific monetary values from these which have received by far the most media attention.

The bulk of this volume, however, focuses more on methodological issues. There are seven chapters. The first introduces the overall framework. The second reviews ecosystem services; the third addresses biophysical indicators; and the fourth provides a sociocultural context. The fifth reviews economic valuation approaches; the sixth looks at discounting options; and the seventh examines policy implications. There are 85 authors and 39 reviewers, including some very well-known environmental economists.

According to the Preface, the study arose from a meeting of 13 environment ministers in 2007, inspired by the Stern Review on the economics of climate change. The theme is that society is changing, and that knowledge, economics, valuation and accounting must change accordingly, so as to mainstream the economics of ecosystems and biodiversity into national and international policies.

The Preface addresses some large-scale questions of particular interest to ecologists. It asks if it is 'ethical to reduce biodiversity ... to mere economics', and whether 'the scientific understanding of ecosystem dynamics ... [may be] ... too weak to support a study of economic implications'. It also asks: 'Why should an economic argument work for biodiversity conservation where ethical, spiritual and social arguments have not been sufficient?' and 'How can we actually evaluate costs, when there are no real alternatives to the living fabric of this planet?' These are certainly fundamental questions.

The limitations of neoclassical economic theory are mentioned briefly, with critiques of 
Walrasian mathematics (p. 20), and Benthamic utility (p. 159). The literature which the book uses, however, is strongly rooted in neoclassical economics, as shown for example in the compendium of valuation mechanisms presented in Chapter 5. Ecological literature is cited in some places, for example in the brief discussion on functional traits in the ecosystem services chapter (p. 50); but very much more sparsely than economic valuation literature.

Indeed, even the valuation literature is far from complete. Using tourism and recreational values as a test, as this is an area where I am most familiar with the literature, I find 29 studies cited for wetlands (Table A 2.1a), and 40 for forests (Table A 2.1b), with considerable overlap. The majority of those studies cited, for both wetlands and forests, are stated-preference methods such as contingent valuation and choice modelling, followed by travel-cost and so-called benefit-transfer methods. Only one single study, and that from 1998, uses a replacement-cost approach: that is, what it would actually cost for the human economy to provide a service currently appropriated for free from the natural world.

Valuation approaches based on production functions and opportunity costs are more common for other types of ecosystem services produced by wetlands and forests: for example, food and water supplies. Even for these, however, the studies listed in these appendices show that it is much easier for economists to publish articles where they simply ask people what they think the natural environment is worth. Such studies, arguably, do not mean a great deal: not merely because of the deficiencies of underlying models, but because people have very little rational basis on which to estimate what any particular ecosystem service is worth. Asking someone in New York, for example, what it is worth to conserve biodiversity in the Amazon is about as meaningful as asking Ecuadorian forest tribes what it is worth to maintain the New York subway system.

From an ecologist's perspective, therefore, the very big numbers which are cited in this book and associated publicity are in fact very much too small. The natural world is worth a very great deal more to humans, than humans think it is. But this is not the point. The Stern Review made politicians think about climate change more seriously because it produced some dollar figures which were large enough to resonate with presidents and billionaires. Whether or not those figures were strictly accurate, matters much less than whether or not those people who shape our world paid any attention to them. The same, I think, will apply to this volume. It does not really produce anything new. The same arguments were made by 
biologists, including myself, in 1990; and by the environmental economists of the Beijer Institute in 1992. But of course, nobody paid attention. If the economists who assembled the TEEB study can indeed attract attention to the value of ecosystems and biodiversity, they will have done a great service to ecologists worldwide.

I will close with a small anecdote. Some years ago the Biological Diversity Advisory Council, an Australian federal body of which I was a member, ran a national conference on the economics of ecosystem biodiversity. On the first day, numerous famous economists explained how to carry out valuations. On the second day, politicians explained that they paid no attention. At that time, the federal government had recently announced the allocation of half a billion dollars to the Murray Darling Initiative, an amount recommended by an economist who was at the conference. This seemed to indicate that politicians did in fact pay attention to economic studies; but the minister denied it and said he had never read the study. Asked why, in that case, he had chosen half a billion dollars, he answered as follows. I remember the exact words very well. It was, he said, 'A nice, round, politically expedient number'.

\section{RALF BUCKLEY}

International Centre for Ecotourism Research, Gold Coast Campus, Griffith University

Queensland, Australia

Email: r.buckley@griffith.edu.au 